\title{
Flexural strength and ductility of reinforced normal- and high-strength concrete beams
}

\author{
H. J. Pam, A. K. H. Kwan and M. S. Islam
}

A number of singly reinforced concrete beams made of normal- and high-strength concretes were tested under monotonically increasing loads to study their flexural behaviour and to compare the flexural ductility of normal- and high-strength concrete beams. The flexural strength results verified that British Standard BS 8II0, after modification as per the recommendation of The Concrete Society Technical Report 49, is reasonably accurate for application to high-strength concrete beams. On the other hand, the flexural ductility results revealed that the major structural parameters determining the ductility of singly reinforced beams are: (I) for given materials, the tension steel ratio; and (2) in more general cases, the tension steel to balanced steel ratio and the concrete grade. Based on the available test results, a simple formula for predicting the ductility of normal- and high-strength concrete beams is developed. Lastly, in order to avoid brittle failure, it is proposed to set a maximum limit to the tension steel to balanced steel ratio, whose values at different concrete strengths are given in the paper.

\section{NOTATION}

$A_{s} \quad$ tension steel area

$A_{s b} \quad$ balanced steel area, i.e. tension steel area that will lead to balanced failure

$b \quad$ breadth

$d \quad$ effective depth to tension reinforcement

$d_{n} \quad$ depth to neutral axis

$f_{c} \quad$ uniaxial compressive strength of concrete

$f_{c u} \quad$ cube compressive strength of concrete

$\boldsymbol{f}_{s} \quad$ axial stress developed in tension reinforcement

$\boldsymbol{f}_{y} \quad$ yield stress of tension reinforcement

$M_{p} \quad$ experimentally measured bending strength

$M_{u} \quad$ theoretically evaluated bending strength

$\alpha \quad$ parameter of equivalent stress block defining the depth of stress block

$\beta \quad$ parameter of equivalent stress block defining the average stress

$\Delta \quad$ deformation

$\Delta_{\max } \quad$ maximum deformation at failure

$\Delta_{y} \quad$ deformation when the member yields

$\varepsilon_{c} \quad$ concrete strain at extreme fibre

$\varepsilon_{c u} \quad$ ultimate concrete strain, i.e. value of $\varepsilon_{c}$ at peak bending moment $\varepsilon_{s} \quad$ axial strain developed in tension reinforcement

$\varepsilon_{y} \quad$ yield strain of tension reinforcement

$\mu \quad$ ductility factor defined by equation (1)

$\rho \quad$ tension steel ratio, i.e. $A_{s} /(b d)$

$\rho_{b} \quad$ balanced steel ratio, i.e. tension steel ratio that will lead to balanced failure

\section{INTRODUCTION}

With the rapid advancement of concrete technology, highstrength concrete is being more widely used in reinforced concrete buildings. Many countries around the world have now raised the upper limit of the concrete strength in their building codes $^{1,2}$ to take into account the higher strength of modern concrete. However, several aspects of the material behaviour of high-strength concrete differ significantly from those of normal-strength concrete and therefore high-strength concrete should not just be regarded as normal concrete with higher strength. For instance, the Young's modulus, tensile strength and shear strength of concrete do not increase in direct proportion to the compressive strength. ${ }^{3,4}$ Hence, in the design of reinforced concrete structures incorporating high-strength concrete, more careful checking of the rigidity, cracking and shear strength of the structures is needed.

Perhaps of greater concern is the generally higher brittleness of high-strength concrete compared to that of normal-strength concrete. ${ }^{3,4}$ High-strength concrete is more brittle in nature because cracks in this material do not always follow the aggregate-hardened cement paste interfaces due to the improved interfacial bond strength of high-strength concrete but may cut right through the hardened cement paste and even the aggregate particles leading to rapid propagation of the cracks and sudden or sometimes explosive failure of the concrete. Because of this problem, many structural engineers hesitate in using high-strength concrete, despite its obvious advantages.

However, the ductility of a reinforced concrete member is not the same as that of the constituting concrete. One common misunderstanding about the ductility of members made of high-strength concrete is the thinking that the ductility of a member made of high-strength concrete is always lower than that of a similar member made of normal-strength concrete. In fact, the ductility of a member is dependent on the type of 
member, the loading arrangement and the reinforcement layout as well as the ductility of the materials used. Detailed ductility evaluation is needed before it is known whether a member made of high-strength concrete has a higher or lower ductility than a similar member made of normal-strength concrete.

In the case of a reinforced concrete column, the major parameters determining its ductility include the axial load ratio, the amount of longitudinal reinforcement, the amount of confining reinforcement and of course the ductility of the concrete used. ${ }^{5,6}$ It is true that for a given column subjected to a prescribed axial load ratio, the use of high-strength concrete in place of normal-strength concrete will significantly reduce the ductility of the column. Nevertheless, the loss in ductility due to the use of high-strength concrete can be replenished by increasing the amount of confining reinforcement. This will put the concrete core under greater confining pressure and substantially increase the ductility of the concrete column. In addition, if necessary, since the axial load capacity is increased, the axial load ratio may be slightly reduced to further improve the ductility of the column. Thus, provided the column to be made of high-strength concrete is properly designed, its ductility can be restored to at least the level of a similar column made of normal-strength concrete.

In the case of a reinforced concrete beam, the major parameters determining its ductility include the amount of tension reinforcement, the amount of compression reinforcement, and the strength and ductility of the materials used. ${ }^{7-9}$ Depending on the amount of reinforcement provided, the tension reinforcement may or may not yield before the concrete in the compression zone is crushed. If the amount of tension reinforcement is small, the tension reinforcement will yield before the concrete is crushed and the beam will fail in a ductile manner. If the amount of tension reinforcement is large, the concrete will be crushed without prior yielding of the tension reinforcement and the beam will fail in a brittle manner. The type of concrete used has, of course, certain effects on the ductility of the beam. When high-strength concrete is used, the concrete will have higher strength but lower ductility. At fixed amounts of tension and compression reinforcement, an increase in concrete strength will reduce the neutral axis depth and increase the strain that will be reached by the tension reinforcement when the concrete is crushed leading to an increase in ductility of the beam. On the other hand, the lower ductility of the concrete does adversely affect the ductility of the beam. Hence, the higher strength and lower ductility of high-strength concrete have opposite effects and the use of high-strength concrete does not necessarily increase or decrease the ductility of the beam. Detailed analysis is needed to evaluate the net effect on the ductility of the beam.

Although the stiffness and strength of reinforced concrete members have been thoroughly studied, there has been relatively little research on the ductility of reinforced concrete members especially those made of high-strength concrete. Herein, a research project aiming to study the ductility of reinforced concrete beams made of normal- and high-strength concretes is presented. In the project, by testing beams with different amounts of longitudinal reinforcement provided and cast from different grades of concrete, the effects of reinforce- ment content and concrete grade on the ductility of reinforced concrete beams were investigated. It is hoped that the results will be useful for practising engineers in predicting and controlling the ductility of reinforced concrete beams.

\section{DUCTILITY FACTOR}

The term 'ductility' is defined as the ability of the material/ member to sustain deformation beyond the elastic limit while maintaining a reasonable load carrying capacity until total failure. Depending on the type of material or member being referred to, the deformation employed to evaluate ductility may be strain, curvature, displacement or rotation. In the particular case of a reinforced concrete beam, the deformation most suited for this purpose is the curvature of the beam. As an alternative, the deflection of the beam, which is generally easier to measure, may also be used. When evaluating ductility, the most important parameter to be considered is the maximum deformation that the material/member can sustain prior to failure. However, two different materials or members having a similar magnitude of maximum deformation at failure can have different stress-strain or load-deflection behaviours and therefore different ductility. For this reason, it is better to express the ductility in terms of a dimensionless ductility factor, $\mu$, as defined below

\begin{tabular}{|l|l|}
\hline $\mathrm{I}$ & $\mu=\frac{\Delta_{\max }}{\Delta_{\mathrm{y}}}$ \\
\hline
\end{tabular}

where $\Delta_{\max }$ is the maximum deformation at failure and $\Delta_{\mathrm{y}}$ is the deformation when the material or member yields.

The determination of $\Delta_{\mathrm{y}}$ can pose difficulties because the loaddeformation curve may not have a well-defined yield point at all. Absence of a well-defined yield point may occur, in the case of a reinforced concrete beam, due to the tension reinforcement at different beam depths reaching yield strain at different times, and in the case of a building frame, due to the plastic hinges in different parts of the structure forming at different load levels. The existing methods used to estimate $\Delta_{\mathrm{y}}$ have been summarised by Park. ${ }^{10}$ Among these, the most practicable and realistic estimation of $\Delta_{\mathrm{y}}$ is the one obtained from an equivalent elasto-plastic system with its equivalent elastic stiffness taken as the secant stiffness at 75\% of the ultimate load of the real system, as shown in Fig. 1. The secant stiffness at a load level significantly higher than the usual cracking load is used instead of the initial elastic stiffness in order to account for the reduction in stiffness due to cracking. This method of determining $\Delta_{\mathrm{y}}$ is adopted in the present study. From Fig. 1, it can be seen that the value of $\Delta_{\mathrm{y}}$ so evaluated is actually equal to $4 / 3$ times the value of $\Delta$ at $75 \%$ of the ultimate load.

The maximum deformation at failure, $\Delta_{\max }$, is dependent on how the failure point is defined because failure is actually a process during which the deformation of the material/member keeps on increasing. Several different definitions have been used to establish a threshold point of failure. ${ }^{10}$ The definition adopted here is the point on the descending part of the loaddeformation curve where the load has dropped to $85 \%$ of the maximum load applied (see Fig. 1). This definition has the advantages that it can be applied to basically all kinds of 
rectangular stress block. From this equation, the neutral axis depth may be determined as

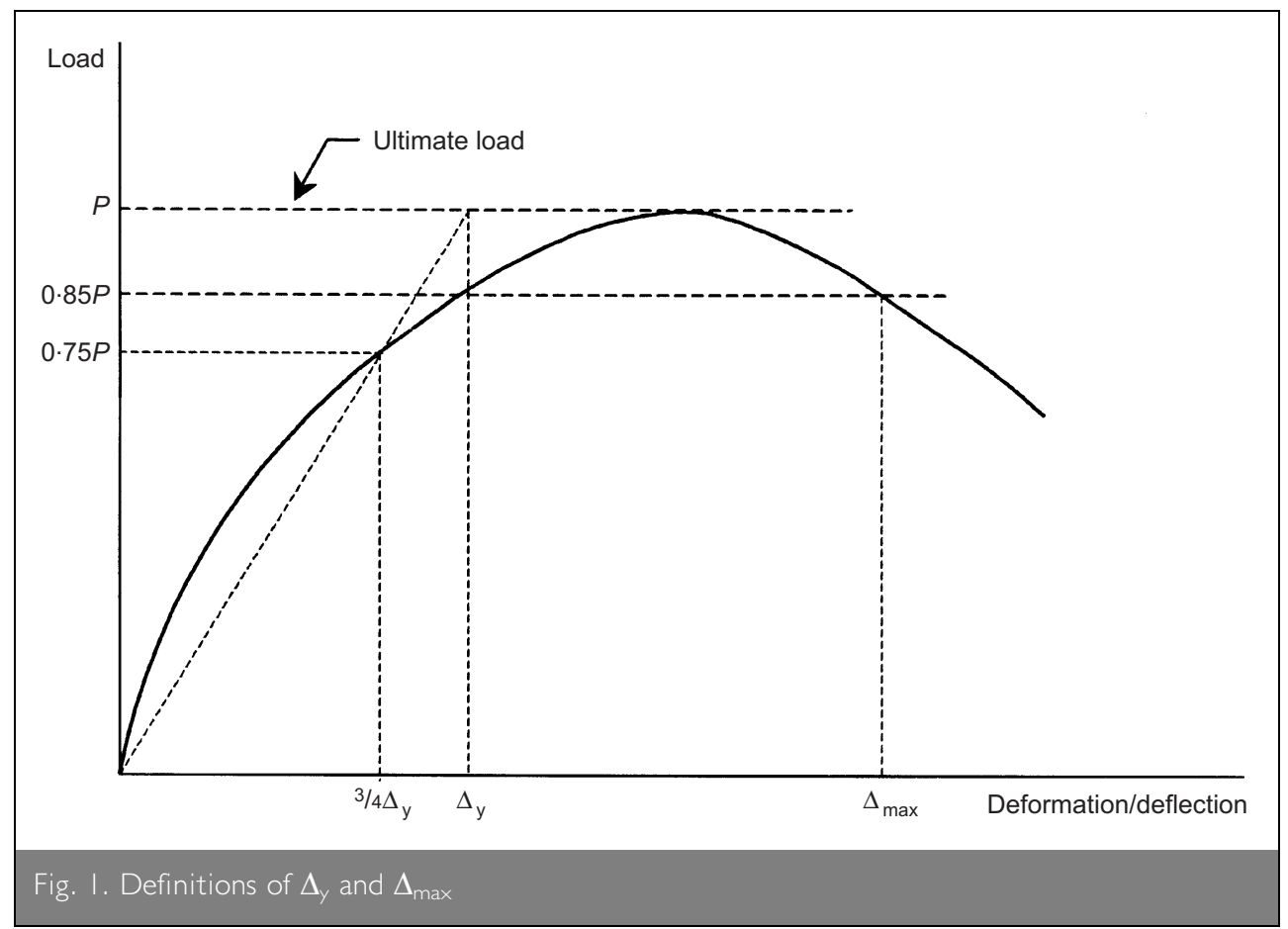

$$
3 \quad d_{\mathrm{n}}=\frac{A_{\mathrm{s}} f_{\mathrm{s}}}{\alpha \beta f_{\mathrm{c}} b}
$$

Having determined the neutral axis depth, the ultimate moment may be evaluated as

$4 \quad M_{\mathrm{u}}=\alpha \beta \boldsymbol{f}_{\mathrm{c}} b d_{\mathrm{n}}\left(d-0 \cdot 5 \alpha d_{\mathrm{n}}\right)$

in which $M_{\mathrm{u}}$ is the ultimate moment and $d$ is the effective depth of the beam.

Depending on the strain reached by the tension reinforcement when the concrete in the compression zone is crushed, the beam may fail with or without prior structures and is relatively easy to determine either analytically or experimentally. Having taken into account the ability of the material/member to deform beyond the peak load, it is regarded as a much better measure of ductility than most other definitions.

\section{FLEXURAL BEHAVIOUR OF REINFORCED CONCRETE BEAMS}

The theoretical ultimate moment of a singly reinforced concrete beam may be calculated using an equivalent rectangular stress block for the concrete as illustrated in Fig. 2. Axial load equilibrium gives

$$
A_{\mathrm{s}} f_{\mathrm{s}}=\alpha \beta f_{\mathrm{c}} b d_{\mathrm{n}}
$$

where $A_{\mathrm{s}}$ is the area of tension reinforcement, $\boldsymbol{f}_{\mathrm{s}}$ is the axial stress developed in the tension reinforcement, $\boldsymbol{f}_{\mathrm{c}}$ is the compressive strength of the concrete, $b$ is the breadth of the beam, $d_{\mathrm{n}}$ is the neutral axis depth, and $\alpha$ and $\beta$ are the coefficients defining the depth and average stress of the equivalent yielding of the tension reinforcement. Assuming plane sections remain plane when the beam is subjected to bending, the axial strain is proportional to the distance from the neutral axis, as shown in Fig. 2. When the concrete strain at the extreme compressive fibre, $\varepsilon_{\mathrm{c}}$, reaches the ultimate concrete strain, $\varepsilon_{\mathrm{cu}}\left(\varepsilon_{\mathrm{cu}}\right.$ is the corresponding value of $\boldsymbol{\varepsilon}_{\mathrm{c}}$ when the beam section delivers greatest moment of resistance), the strain of the tension reinforcement, $\varepsilon_{\mathrm{s}}$, reaches the following value

$$
\varepsilon_{\mathrm{s}}=\frac{d-d_{\mathrm{n}}}{d_{\mathrm{n}}} \varepsilon_{c u}
$$

Denoting the yield strain of the tension reinforcement by $\varepsilon_{\mathrm{y}}$ and comparing the above value of $\varepsilon_{\mathrm{s}}$ to $\varepsilon_{\mathrm{y}}$, the failure mode of the beam can be determined as follows: If $\varepsilon_{\mathrm{s}}$ is greater than $\boldsymbol{\varepsilon}_{\mathrm{y}}$, the tension reinforcement will yield before the concrete is crushed (tension failure). If $\boldsymbol{\varepsilon}_{\mathrm{s}}$ is smaller than $\boldsymbol{\varepsilon}_{\mathrm{y}}$, the concrete will be crushed without prior yielding of the tension reinforcement (compression failure). If $\varepsilon_{\mathrm{s}}$ is equal to $\boldsymbol{\varepsilon}_{\mathrm{y}}$, the tension reinforcement will yield at the same time when the concrete is crushed (balanced failure). From equation (5), the condition for balanced failure is obtained as

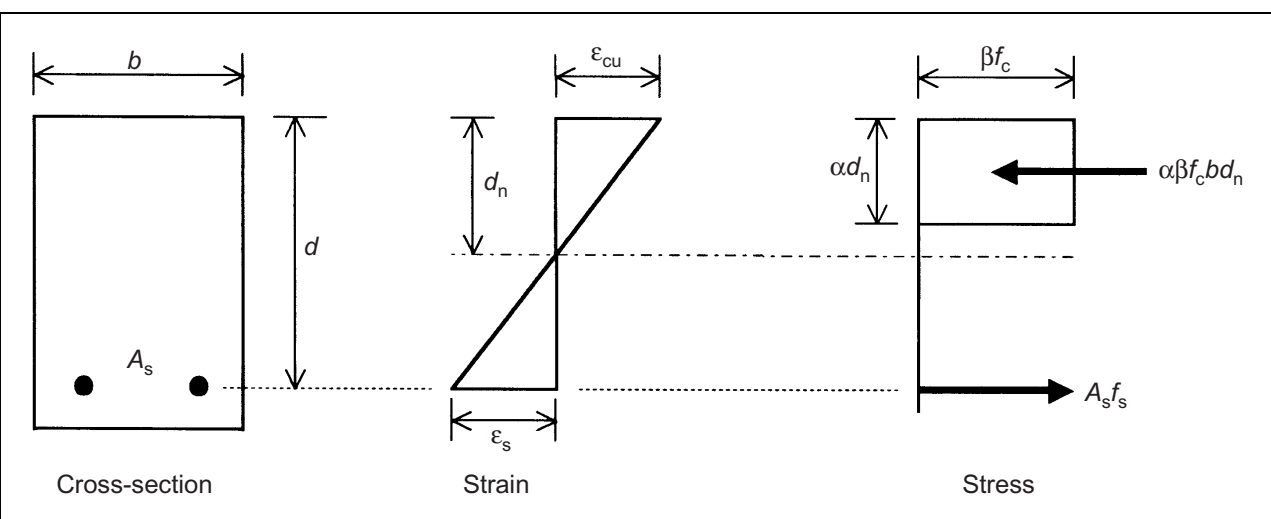

Fig. 2. Equivalent rectangular stress block for concrete

\begin{tabular}{|l|l|}
\hline 6 & $\frac{d_{\mathrm{n}}}{d}=\frac{\varepsilon_{\mathrm{cu}}}{\varepsilon_{\mathrm{cu}}+\varepsilon_{\mathrm{y}}}$ \\
\hline
\end{tabular}

Using equation (2), the amount of tension reinforcement that will lead to balanced failure, $A_{\mathrm{sb}}$, may be determined as

\begin{tabular}{|l|l|}
\hline 7 & $A_{\mathrm{sb}}=\alpha \beta \frac{f_{\mathrm{c}}}{f_{\mathrm{y}}} \frac{\varepsilon_{\mathrm{cu}}}{\varepsilon_{\mathrm{cu}}+\varepsilon_{\mathrm{y}}} b d$ \\
\hline
\end{tabular}

in which $\boldsymbol{f}_{\mathrm{y}}$ is the yield stress of the tension reinforcement. Expressing the area of tension reinforcement in 
dimensionless form as a tension steel ratio, $\rho$, defined by $\rho=A_{\mathrm{s}} /(b d)$, the balanced steel ratio, $\rho_{\mathrm{b}}$, i.e. the tension steel ratio that will lead to balanced failure, can be obtained as

$$
8 \quad \rho_{\mathrm{b}}=\alpha \beta \frac{f_{\mathrm{c}}}{f_{\mathrm{y}}} \frac{\varepsilon_{\mathrm{cu}}}{\varepsilon_{\mathrm{cu}}+\varepsilon_{\mathrm{y}}}
$$

If $\rho$ is less than $\rho_{\mathrm{b}}$ (underreinforced), the tension reinforcement will yield before the concrete is crushed and the beam will fail in a ductile manner. If $\rho$ is greater than $\rho_{\mathrm{b}}$ (over-reinforced), the tension reinforcement will not yield even when the concrete is crushed and the beam will fail in a brittle manner.

\section{PARAMETERS OF CONCRETE STRESS BLOCK}

The compressive stress-strain curve of high-strength concrete differs quite significantly from that of normal-strength concrete. ${ }^{3,4}$ Relatively, the compressive stress-strain curve of high-strength concrete has the following characteristics

(a) the ascending part is more linear

(b) the strain at peak stress is larger

(c) the descending part is steeper

(d) the ultimate strain is smaller.

Thus, the rectangular stress block designed for normal-strength concrete should not be used indiscriminately for high-strength concrete. Without going into too much sophistication, it is suggested to follow the recommendation of The Concrete Society as given in its Technical Report 49. ${ }^{11}$ According to the recommendation of The Concrete Society, the parabolicrectangular stress-strain curve given in British Standard BS $8110,{ }^{12}$ which was originally developed for normal-strength concrete, may be used for high-strength concrete provided the ultimate concrete strain, $\varepsilon_{\mathrm{cu}}$, is modified as shown below when $f_{\text {cu }} \leq 60 \mathrm{MPa}, \quad \varepsilon_{\mathrm{cu}}=0.0035$ when $f_{\text {cu }}>60 \mathrm{MPa}, \quad \varepsilon_{\mathrm{cu}}=0.0035-\left(f_{\mathrm{cu}}-60\right) / 50000$
Table 1. Having evaluated the values of $\varepsilon_{\mathrm{cu}}, \alpha$ and $\beta$, the balanced steel ratios for different concrete strengths and different types of tension reinforcement are calculated using equation (8) and are listed in columns 5 and 6 of Table 1. It can be seen from the results tabulated in Table 1 that as the concrete strength increases, the balanced steel ratio also increases.

\section{TESTING PROGRAMME}

Twenty rectangular singly reinforced concrete beams having dimensions $200 \mathrm{~mm} \times 300 \mathrm{~mm} \times 3000 \mathrm{~mm}$ (breadth $\times$ depth $\times$ length) were fabricated for testing. The beams were cast from normal- or high-strength concrete with cube compressive strength ranging from 35 to $100 \mathrm{MPa}$. In order to study the effects of different amounts of reinforcement, the main reinforcement provided was varied from $0 \cdot 8$ to $5 \cdot 5 \%$ of the effective beam section area. All the main reinforcement bars used were high-yield steel bars with yield strength within 520 to $580 \mathrm{MPa}$. The main bars were placed near the bottom of the beams. Near the top of the beams, two $12 \mathrm{~mm}$ diameter bars were added as hanger bars for fixing the stirrups. At the ends of the main bars, generous anchorage in the form of $90^{\circ}$ hooks was provided to prevent bond-slip of the reinforcement bars. The stirrups added, which served as shear reinforcement, were designed such that the beams would fail only in bending, not in shear. All of the beams were simply supported at a span of $2600 \mathrm{~mm}$ and were tested by subjecting them to two monotonically applied point loads near mid-span, as illustrated in Fig. 3. Detailed properties of the beams are given in Table 2.
The stress block given in BS 8110 consists of two portions, a parabolic portion and a rectangular portion. It is converted to an equivalent rectangular stress block as shown in Fig. 2 before being applied to the analysis in the present study. Considering the equilibrium conditions, the values of $\alpha$ and $\beta$ defining the depth and average stress of the equivalent rectangular stress block for different concrete strengths are evaluated and the results are presented in

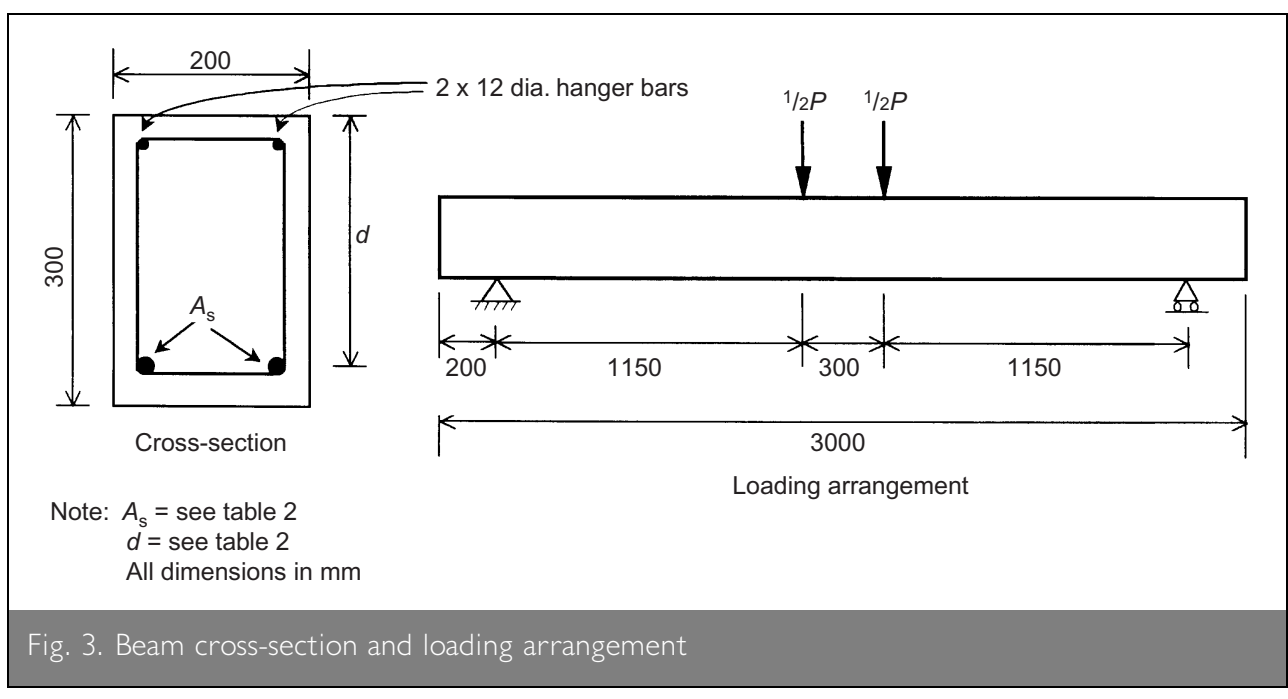




\begin{tabular}{|c|c|c|c|c|c|}
\hline \multirow[t]{2}{*}{ Beam no. } & \multirow[t]{2}{*}{$f_{\mathrm{cu}}: \mathrm{MPa}$} & \multirow[t]{2}{*}{$\mathrm{d}: \mathrm{mm}$} & \multicolumn{3}{|c|}{ Main reinforcement } \\
\hline & & & Layout & $A_{s}: m^{2}$ & $f_{y}: M P a$ \\
\hline । & $37 \cdot 4$ & 264 & $2 T 16$ & 402 & 579 \\
\hline 2 & $36 \cdot 8$ & 264 & $3 T 16$ & 603 & 579 \\
\hline 3 & $36 \cdot 4$ & 260 & $2 T 25$ & 982 & 578 \\
\hline 4 & $42 \cdot 3$ & 260 & $2 \mathrm{~T} 25$ & 982 & 536 \\
\hline 5 & $46 \cdot 4$ & 260 & $2 \mathrm{~T} 25+1 \mathrm{~T} 16$ & 1183 & 546 \\
\hline 6 & $43 \cdot 2$ & 260 & $3 \mathrm{~T} 25$ & 1473 & 536 \\
\hline 7 & $58 \cdot 6$ & 260 & $2 \mathrm{~T} 25+\mathrm{IT} 20$ & 1296 & 520 \\
\hline 8 & $57 \cdot 1$ & 260 & $3 \mathrm{~T} 25$ & 1473 & 520 \\
\hline 9 & $58 \cdot 6$ & 256 & $2 T 32+1 T 16$ & 1809 & 520 \\
\hline 10 & $50 \cdot 3$ & 256 & $2 T 32+1 T 25$ & 2099 & 519 \\
\hline | | & $58 \cdot 8$ & 256 & $2 T 32+1 T 25$ & 2099 & 519 \\
\hline 12 & $52 \cdot 9$ & 256 & 3Т32 & 2414 & 519 \\
\hline 13 & $58 \cdot 8$ & 256 & $3 T 32+2 T 16$ & 2815 & 520 \\
\hline 14 & $95 \cdot 5$ & 260 & $2 T 25$ & 982 & 578 \\
\hline 15 & $98 \cdot 0$ & 260 & $3 T 25$ & 1473 & 578 \\
\hline 16 & $102 \cdot 5$ & 260 & $3 T 25$ & 1473 & 578 \\
\hline 17 & $87 \cdot 0$ & 256 & $2 T 32$ & 1608 & 546 \\
\hline 18 & $90 \cdot 3$ & 256 & $3 T 32$ & 2414 & 574 \\
\hline 19 & $91 \cdot 7$ & 256 & $3 \mathrm{~T} 32$ & 2414 & 574 \\
\hline 20 & $83 \cdot 5$ & 256 & $3 T 32+2 T 16$ & 2815 & 553 \\
\hline
\end{tabular}

Their failure was more abrupt and sometimes even quite explosive due to brittle failure of the concrete without prior yielding of the tension reinforcement. The balancedreinforced beams behaved in an intermediate manner between those of underreinforced and overreinforced beams, but generally they appeared to fail in a fairly brittle manner.

Due to the practical difficulty of accurate curvature measurement, the curvatures of the beams were not measured and only the deflections of the beams were obtained. Hence, instead of moment-curvature curves, the deformation behaviour of the beam specimens was studied in terms of momentdeflection curves. Some typical moment-deflection

The loads were applied using a $500 \mathrm{kN}$ computer controlled hydraulic actuator manufactured by MTS. During loading, the vertical deflections at mid-span of the beams were measured by a displacement transducer. The strains in the main reinforcement bars were measured by electrical resistance strain gauges glued at the location where maximum bending moment was expected. Visual inspection of the cracks was carried out throughout the tests and the crack patterns were recorded by a video camera. At the initial stage, the test was conducted using load control up to $75 \%$ of the theoretical ultimate load. Subsequently, the test was conducted using displacement control in order to capture the post-peak behaviour of the beam specimen. The test was terminated when the specimen failed completely, i.e. when the resistance of the specimen dropped to less than $85 \%$ of the measured ultimate load.

\section{EXPERIMENTAL RESULTS}

In terms of tension steel content, the beam specimens can be divided into three groups: under-reinforced beams, balancedreinforced beams and over-reinforced beams. The different groups of beams were found to behave similarly at the elastic stage but quite differently during failure. In all the beams, fine vertical tension cracks started to appear near the mid-span region when the applied load reached about 50 to $60 \%$ of the ultimate load. Upon further loading, the flexural cracks developed in length and width, as well as increased in number. At the same time, some inclined cracks occurred between the support and the point of load application, i.e. within the region of bending moment and shear interaction. For the underreinforced beams, regardless of the grade of the concrete used, extensive tension cracks were formed before peak load was reached. Failure of these beams was gradual and smooth, and was accompanied by fairly large deflection. For the overreinforced beams, particularly those made of high-strength concrete, there were generally fewer number of tension cracks. curves (those of beams no. 2, no. 8 and no. 20) obtained from the tests are shown in Fig. 4. Beam no. 2, which was cast from concrete with relatively low cube strength $\left(f_{\mathrm{cu}}=36 \cdot 8 \mathrm{MPa}\right)$ and was under-reinforced $\left(\rho / \rho_{\mathrm{b}}=0 \cdot 57\right)$, exhibited a fairly ductile moment-deflection behaviour. Beam no. 8 , which was made of normal-strength concrete $\left(\boldsymbol{f}_{\mathrm{cu}}=57 \cdot 1 \mathrm{MPa}\right)$ and was provided with nearly balanced reinforcement $\left(\rho / \rho_{\mathrm{b}}=0 \cdot 82\right)$, exhibited a somewhat less ductile behaviour. On the other hand, beam no. 20, which was cast from high-strength concrete $\left(f_{\mathrm{cu}}=83 \cdot 5 \mathrm{MPa}\right)$ and was over-reinforced $\left(\rho / \rho_{\mathrm{b}}=1 \cdot 37\right)$, failed in a rather brittle manner. It is thus evident that both the concrete grade and the $\rho / \rho_{\mathrm{b}}$ ratio have certain effects on the flexural ductility of reinforced concrete beams.

From the load measurement results and the moment-deflection curves of the beam specimens, the ultimate moment, $M_{\mathrm{p}}$, and ductility factor, $\mu$, of each specimen can be obtained. These

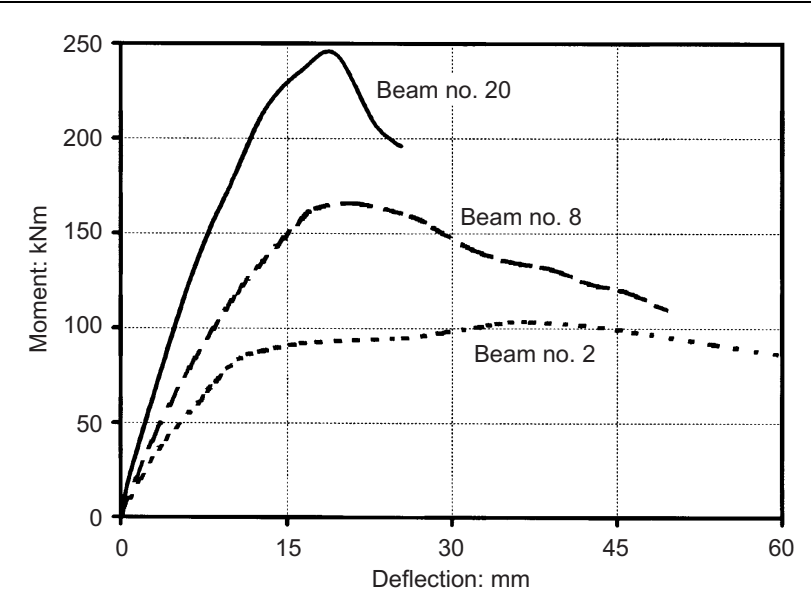

Fig. 4. Typical moment-deflection curves 
results, together with the tension steel ratio, $\rho$, balanced steel ratio, $\rho_{\mathrm{b}}$, tensile steel to balanced steel ratio, $\rho / \rho_{\mathrm{b}}$, and the theoretically evaluated values of ultimate strength, $M_{\mathrm{u}}$, are presented in Table 3 and analysed next.

\section{I. Flexural strength analysis}

In the present study, the theoretical ultimate moment, $M_{\mathrm{u}}$, is evaluated using the parabolic-rectangular stress-strain curve given in British Standard BS $8110^{12}$ and the recommended formula for $\boldsymbol{\varepsilon}_{\mathrm{cu}}$ given in The Concrete Society Technical Report $49 .{ }^{11}$ The experimental values of ultimate moment, $M_{\mathrm{p}}$, are compared to the corresponding theoretical values $M_{\mathrm{u}}$ in terms of $M_{\mathrm{p}} / M_{\mathrm{u}}$ ratios, which are listed in Table 3. It is seen that the $M_{\mathrm{p}} / M_{\mathrm{u}}$ ratios for beams with $f_{\mathrm{cu}} \approx 37 \mathrm{MPa}$ are around $1 \cdot 11$ to $1 \cdot 39$, those for beams with $f_{\mathrm{cu}} \approx 44 \mathrm{MPa}$ are around $1 \cdot 07$ to $1 \cdot 15$, those for beams with $f_{\text {cu }} \approx 56 \mathrm{MPa}$ are around 0.94 to 1.22 and those for beams with $f_{\mathrm{cu}} \approx 93 \mathrm{MPa}$ are around 0.91 to $1 \cdot 22$. It may be said, therefore, that the experimental values of ultimate moment generally agree quite closely with the corresponding theoretical values. Thus, the applicability of BS 8110, after modification as suggested by The Concrete Society, to high-strength concrete beams is confirmed.

In most cases, the experimental values of ultimate moment are slightly higher than the corresponding theoretical values. The difference between the experimental and theoretical ultimate moments serves as a kind of strength reserve. For those beams made of concrete with $f_{\mathrm{cu}}<50 \mathrm{MPa}$, the experimental values of ultimate moment are always higher than the corresponding theoretical values, leading to an average $M_{\mathrm{p}} / M_{\mathrm{u}}$ ratio of $1 \cdot 19$, which is significantly higher than 1 . On the other hand, for those beams with $f_{\mathrm{cu}} \approx 56 \mathrm{MPa}$, the average $M_{\mathrm{p}} / M_{\mathrm{u}}$ ratio is equal to only about $1 \cdot 11$ and for those beams with $f_{\mathrm{cu}} \approx 93 \mathrm{MPa}$, the average $M_{\mathrm{p}} / M_{\mathrm{u}}$ ratio is even lower at around $1 \cdot 02$. It appears, therefore, that the amount of such strength reserve varies with the concrete grade and is generally smaller at higher concrete strength.

\subsection{Flexural ductility analysis}

The ductility of a beam specimen is evaluated in terms of its ductility factor, $\mu$, which is measured from the momentdeflection curve, and the results are listed in the last column of Table 3. It is found that the $\mu$-values obtained are a bit scattered. This is understandable because a small change in the shape of the moment-deflection curve can lead to a relatively large change in the value of $\mu$ and hence a small error in the measurement of the moment-deflection curve could produce a significant error in $\mu$. Nevertheless, by statistically correlating the $\mu$-values to the corresponding structural parameters of the beam specimens, the major parameters affecting the ductility of concrete beams can be identified and their effects studied. The $\mu$-values are plotted against the corresponding tension steel ratios, $\rho$, in Fig. 5. Despite the scattering of the $\mu$-values, an obvious trend

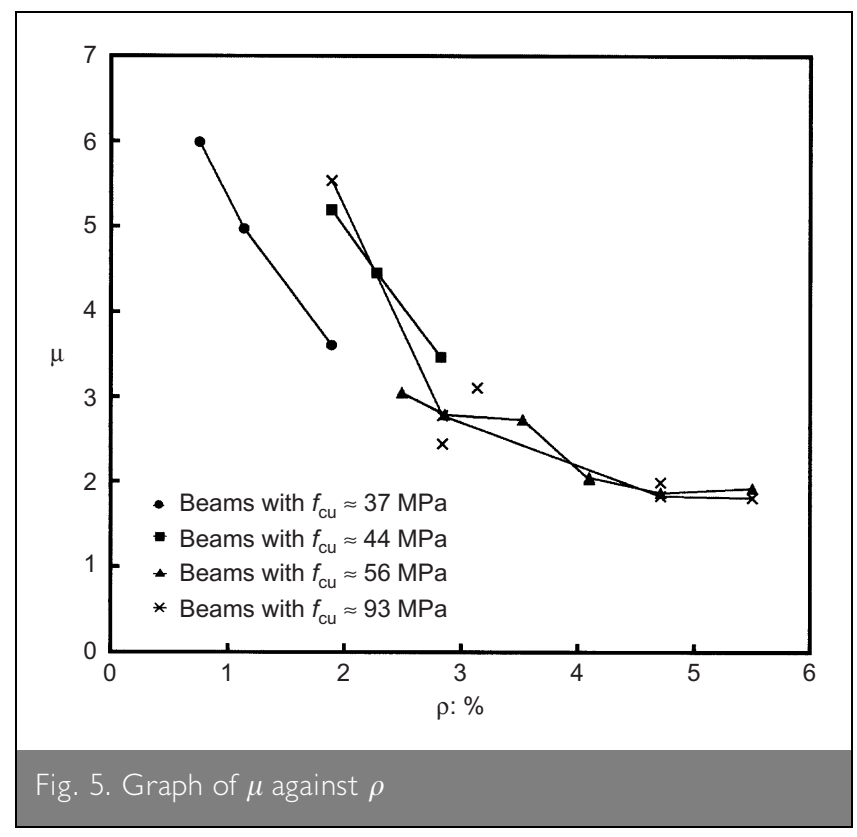

\begin{tabular}{|c|c|c|c|c|c|c|c|c|}
\hline Beam no. & $f_{c u}: M P a$ & $\rho: \%$ & $\rho_{\mathrm{b}}: \%$ & $\rho / \rho_{\mathrm{b}}$ & $M_{p}: k N m$ & $M_{\mathrm{u}}: \mathrm{kNm}$ & $M_{p} / M_{u}$ & $\mu$ \\
\hline I & $37 \cdot 4$ & 0.76 & $2 \cdot 04$ & $0 \cdot 37$ & $77 \cdot 6$ & $56 \cdot 0$ & $1 \cdot 39$ & 5.99 \\
\hline 2 & $36 \cdot 8$ & $|\cdot| 4$ & $2 \cdot 01$ & $0 \cdot 57$ & $103 \cdot 5$ & $79 \cdot 7$ & $1 \cdot 30$ & 4.97 \\
\hline 3 & $36 \cdot 4$ & 1.89 & 1.99 & 0.95 & $126 \cdot 5$ & $1 \mid 4 \cdot 1$ & $|\cdot| \mid$ & $3 \cdot 61$ \\
\hline 4 & $42 \cdot 3$ & $1 \cdot 89$ & $2 \cdot 55$ & 0.74 & $129 \cdot 0$ & $112 \cdot 0$ & $\mid \cdot 15$ & $5 \cdot 19$ \\
\hline 5 & $46 \cdot 4$ & $2 \cdot 28$ & $2 \cdot 70$ & 0.84 & $142 \cdot 8$ & $133 \cdot 8$ & 1.07 & 4.45 \\
\hline 6 & $43 \cdot 2$ & $2 \cdot 83$ & $2 \cdot 60$ & 1.09 & $162 \cdot 0$ & $144 \cdot 8$ & $1 \cdot 12$ & $3 \cdot 46$ \\
\hline 7 & $58 \cdot 6$ & $2 \cdot 49$ & $3 \cdot 57$ & $0 \cdot 70$ & $164 \cdot 6$ & $145 \cdot 7$ & $1 \cdot 13$ & 3.05 \\
\hline 8 & $57 \cdot 1$ & $2 \cdot 86$ & $3 \cdot 50$ & $0 \cdot 82$ & $166 \cdot 2$ & $160 \cdot 6$ & 1.03 & $2 \cdot 79$ \\
\hline 9 & $58 \cdot 6$ & $3 \cdot 53$ & $3 \cdot 57$ & 0.99 & 171.6 & $183 \cdot 2$ & 0.94 & $2 \cdot 73$ \\
\hline 10 & $50 \cdot 3$ & $4 \cdot 10$ & $3 \cdot 12$ & $|\cdot 3|$ & 197.5 & 169.7 & $1 \cdot 16$ & $2 \cdot 03$ \\
\hline II & $58 \cdot 8$ & $4 \cdot 10$ & $3 \cdot 59$ & $1 \cdot 14$ & $213 \cdot 5$ & $190 \cdot 3$ & $1 \cdot 12$ & $2 \cdot 05$ \\
\hline 12 & $52 \cdot 9$ & $4 \cdot 71$ & $3 \cdot 26$ & $1 \cdot 44$ & $219 \cdot 7$ & 179.7 & $1 \cdot 22$ & |.87 \\
\hline 13 & $58 \cdot 8$ & $5 \cdot 50$ & $3 \cdot 58$ & $1 \cdot 54$ & $239 \cdot 7$ & $200 \cdot 3$ & $1 \cdot 20$ & 1.92 \\
\hline 14 & $95 \cdot 5$ & 1.89 & 3.91 & 0.48 & 138.0 & $134 \cdot 0$ & $\mid \cdot 03$ & $5 \cdot 54$ \\
\hline 15 & $98 \cdot 0$ & $2 \cdot 84$ & 3.93 & $0 \cdot 72$ & $200 \cdot 7$ & $191 \cdot 4$ & 1.05 & $2 \cdot 45$ \\
\hline 16 & $102 \cdot 5$ & $2 \cdot 84$ & 3.94 & 0.72 & $181 \cdot 7$ & 192.4 & 0.94 & $2 \cdot 78$ \\
\hline 17 & $87 \cdot 0$ & $3 \cdot 14$ & $4 \cdot 15$ & 0.76 & $172 \cdot 0$ & 189.9 & 0.91 & $3 \cdot 11$ \\
\hline 18 & $90 \cdot 3$ & $4 \cdot 71$ & $3 \cdot 90$ & $|\cdot 2|$ & $301 \cdot 9$ & $247 \cdot 1$ & $\mid \cdot 22$ & 1.83 \\
\hline 19 & $91 \cdot 7$ & $4 \cdot 71$ & 3.93 & $1 \cdot 20$ & $253 \cdot 6$ & $248 \cdot 6$ & 1.02 & 1.99 \\
\hline 20 & $83 \cdot 5$ & $5 \cdot 50$ & $4 \cdot 01$ & $1 \cdot 37$ & $244 \cdot 7$ & $247 \cdot 6$ & 0.99 & $|\cdot 8|$ \\
\hline
\end{tabular}


showing that the ductility decreases as the tension steel ratio increases is revealed. In any case, for beams made of given materials, the major factor affecting their ductility appears to be the tension steel ratio.

The effect of the tension steel ratio, $\rho$, on the ductility of a beam is dependent on the properties of the materials used. Since whether the beam is under-reinforced $\left(\rho / \rho_{\mathrm{b}}<1\right)$ or overreinforced $\left(\rho / \rho_{\mathrm{b}}>1\right)$ should be more important in determining the ductility of a beam, it is suggested that the $\mu$-values should better be correlated to the tension steel to balanced steel ratios as depicted in Fig. 6. It can be seen from the curves plotted that the reinforced concrete beams made of different grades of concrete lead to different $\mu /\left(\rho / \rho_{\mathrm{b}}\right)$ curves. Except for a few anomalous cases, at similar $\rho / \rho_{\mathrm{b}}$ ratios, the ductility factors are generally lower at higher concrete strengths and higher at lower concrete strengths. On the other hand, for a given concrete strength, the ductility factor, $\mu$, is higher when the $\rho / \rho_{\mathrm{b}}$ ratio is small and lower when the $\rho / \rho_{\mathrm{b}}$ ratio is large.

It appears from the above that in general cases, the major structural parameters affecting the ductility of a singly reinforced concrete beam are the tension steel to balanced steel ratio, $\rho / \rho_{\mathrm{b}}$, and the concrete grade. Assuming that the ductility factor, $\mu$, is a function of $\rho / \rho_{\mathrm{b}}$ and $\boldsymbol{f}_{\mathrm{cu}}$ as given by the following equation

$$
\mu=k\left(\boldsymbol{f}_{\mathrm{cu}}\right)^{m}\left(\rho / \rho_{\mathrm{b}}\right)^{n}
$$

and using regression analysis to determine the values of $k, m$ and $n$, the correlation equation for estimating $\mu$ from $\rho / \rho_{\mathrm{b}}$ and $f_{\text {cu }}$ is obtained as $\mu=9 \cdot 5\left(f_{\mathrm{cu}}\right)^{-0.3}\left(\rho / \rho_{\mathrm{b}}\right)^{-0.75}$

The correlation coefficient, $R$, of the above equation is found to be $0 \cdot 886$. In order to visualise how good the correlation is, the experimental values of $\mu$ are plotted against the corresponding theoretical values in Fig. 7. Although high accuracy cannot be expected, the equation does reveal how the ductility factor, $\mu$, varies with the two parameters $\rho / \rho_{\mathrm{b}}$ and $\boldsymbol{f}_{\mathrm{cu}}$.

To avoid brittle failure and ensure minimum ductility, it is generally considered good practice to limit the tension steel ratio, $\rho$, to not more than $75 \%$ of the balanced steel ratio, $\rho_{\mathrm{b}}$. Since this practice has been adopted for a long time before the advent of high-strength concrete, this presumably applies mainly to beams made of normal-strength concrete. In order to maintain a similar level of ductility, it is proposed that for beams made of high-strength concrete, the $\rho / \rho_{\mathrm{b}}$ ratio should be limited to a certain maximum value such that the ductility factor of the beam as evaluated by equation (11) is not less than that of a beam with $\boldsymbol{f}_{\mathrm{cu}}=50 \mathrm{MPa}$ and $\rho / \rho_{\mathrm{b}}=0 \cdot 75$. The recommended maximum $\rho / \rho_{\mathrm{b}}$ ratio may be evaluated by

\begin{tabular}{|l|l|}
\hline 12 & $\left(f_{\mathrm{cu}}\right)^{-0.3}\left(\rho / \rho_{\mathrm{b}}\right)^{-0.75}=(50)^{-0.3}(0.75)^{-0.75}$ \\
\hline
\end{tabular}

which gives

For easy reference, the maximum values of $\rho / \rho_{\mathrm{b}}$ for different grades of concrete are tabulated in Table 4.

It can be seen from the values listed that when high-strength concrete is used, the maximum $\rho / \rho_{\mathrm{b}}$ ratio needs to be reduced to avoid brittle failure. Nevertheless, since $\rho_{\mathrm{b}}$ increases with the concrete strength, the maximum value of $\rho$, which is equal to $\rho_{\mathrm{b}}$ times the maximum $\rho / \rho_{\mathrm{b}}$ ratio, still increases with the concrete strength until $\boldsymbol{f}_{\mathrm{cu}}=80 \mathrm{MPa}$. Thus, the use of highstrength concrete in place of normal-strength concrete does allow the use of a slightly higher value of $\rho$ to increase the bending strength of the beam while maintaining similar ductility (see Table 4). For instance, the use of a high-strength concrete with $f_{\mathrm{cu}}=80 \mathrm{MPa}$ in place of a normal-strength concrete with $f_{\mathrm{cu}}=50 \mathrm{MPa}$ allows us to increase the tension steel ratio, $\rho$, from $2 \cdot 76$ to $3 \cdot 19 \%$ which could lead to an
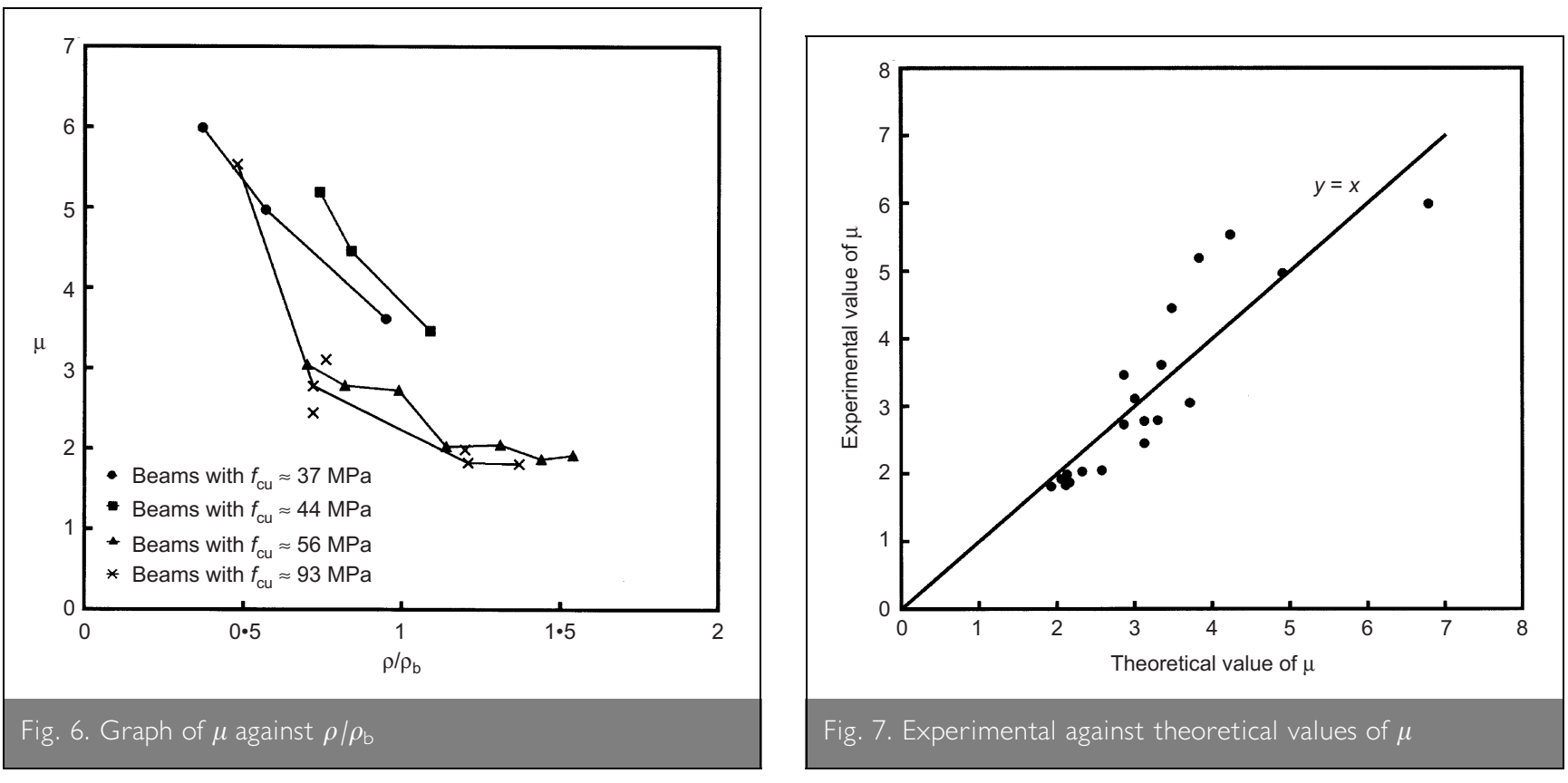


\begin{tabular}{|c|c|c|c|c|}
\hline$f_{\text {cu: }}: \mathrm{MPa}$ & $\rho_{\mathrm{b}}: \%$ & $\operatorname{Max} . \rho / \rho_{\mathrm{b}}$ & Max. $\rho: \%$ & $\begin{array}{c}\operatorname{Max} \cdot \frac{M_{u}}{b d^{2}} \\
M P a\end{array}$ \\
\hline 40 & $3 \cdot 00$ & 0.75 & $2 \cdot 25$ & $8 \cdot 33$ \\
\hline 50 & $3 \cdot 68$ & 0.75 & $2 \cdot 76$ & $10 \cdot 25$ \\
\hline 60 & $4 \cdot 34$ & 0.70 & 3.04 & 11.48 \\
\hline 70 & $4 \cdot 78$ & 0.66 & $3 \cdot 15$ & $12 \cdot 21$ \\
\hline 80 & $5 \cdot 14$ & 0.62 & $3 \cdot 19$ & 12.57 \\
\hline 90 & $5 \cdot 40$ & 0.59 & $3 \cdot 19$ & 12.75 \\
\hline 100 & $5 \cdot 54$ & 0.57 & $3 \cdot 16$ & $12 \cdot 81$ \\
\hline
\end{tabular}

increase in bending strength, $M_{\mathrm{u}}$, of about $23 \%$. It is only that the net allowable increase in bending strength due to the use of high-strength concrete is not that great (only 23\% increase in bending strength even when the concrete strength $f_{\text {cu }}$ is increased by $60 \%$ from 50 to $80 \mathrm{MPa}$ ) and therefore the use of high-strength concrete in reinforced concrete beams may not be a worthwhile pursuit unless there is no better alternative. For high-strength concrete, especially concrete with $f_{\mathrm{cu}}>80 \mathrm{MPa}$, to be more useful in beams, its ductility needs to be improved by, say, the provision of confinement or fibre reinforcement.

\section{CONCLUSIONS}

The flexural strength and ductility of singly reinforced concrete beams made of normal- and high-strength concretes have been studied experimentally. Analysis of the test results leads to the following conclusions.

(a) The experimental results for flexural strength agree quite closely with the theoretical predictions using the parabolic-rectangular stress block given in British Standard BS 8110 and the ultimate concrete strain recommended by The Concrete Society Technical Report 49 , thus verifying the applicability of BS 8110, after modification as per Concrete Society recommendation, to high-strength concrete beams. However, the strength reserve that is normally available when normal-strength concrete is used gradually decreases as the concrete strength increases.

(b) The major structural parameters determining the flexural ductility of singly reinforced concrete beams are, for given materials, the tension steel ratio and, in general cases, the tension steel to balanced steel ratio and the concrete grade. Based on the available test results and using regression analysis, a simple formula for estimating the flexural ductility of normal- and high-strength concrete beams is developed. This formula, though not expected to be very accurate, can at least serve as a guideline for ductility evaluation and control.

(c) To avoid brittle failure and ensure minimum ductility, it is proposed to set a maximum limit to the tension steel to balanced steel ratio. The values of the proposed maximum limit, which gradually decreases as the concrete strength increases to account for the lower ductility of higher strength concrete, have been listed in Table 4. Nevertheless, since the balanced steel ratio increases with the concrete strength, the maximum allowable tension steel ratio still increases with the concrete strength until $f_{\text {cu }}=80 \mathrm{MPa}$. Thus, the use of high-strength concrete in place of normalstrength concrete does allow the bending strength of the beam to be increased while maintaining similar ductility. However, the net increase in bending strength due to the use of high-strength concrete is relatively small compared to the increase in concrete strength.

(d) The further increase in strength of the concrete to be used in reinforced concrete beams beyond the level of $f_{\text {cu }}=80 \mathrm{MPa}$ offers little advantage when both the strength and ductility of the beams have to be considered. For highstrength concrete with $f_{\mathrm{cu}}>80 \mathrm{MPa}$ to be more useful in beam structures its ductility needs to be significantly improved.

\section{ACKNOWLEDGEMENTS}

The authors wish to acknowledge financial support from the Research Grants Council of Hong Kong (Project Reference No. HKU 434/94E) and to express their appreciation to the technical staff in the Structures Laboratory of The University of Hong Kong for their help in conducting the experiment.

\section{REFERENCES}

1. European Committee for Standardization. Eurocode 2: design of concrete structures, part 1-1: general rules and rules for buildings (ENV 1992-1-1). Concrete Structures Euro-Design Handbook. Ernst \&t Sohn Verlag fur Architektur und Technische Wissenschaften GmbH, Berlin, 1992.

2. Aci Commitree 318. Building Code Requirements for Structural Concrete (ACI 318M-95) and Commentary (ACI 318RM-95). American Concrete Institute, Detroit, 1995.

3. FIP-CEB. High Strength Concrete: State of the Art Report, CEB Bulletin d'Information No. 197, FIP State of the Art Report SR 90/1. Thomas Telford Ltd, London, 1990.

4. Aci Commitree 363. State-of-the-Art Report on High Strength Concrete, ACI 363R-92. American Concrete Institute, Detroit, 1992.

5. YoNG Y. K., Nour M. and NAWY E. G. Behavior of laterally confined high-strength concrete under axial loads. Journal of Structural Engineering, ASCE, 1988, 114, No. 2, 332-350.

6. SaAtcioglu M. and Razvi S. R. Strength and ductility of confined concrete. Journal of Structural Engineering, ASCE, 1992, 118, No. 6, 1590-1607.

7. LESLIE K. E., RAJAGOPALAN K. S. and EVERARD N. J. Flexural behavior of high-strength concrete beams. ACI Journal, 1976, 73, 517-521.

8. Shin S., Ghosh S. K. and Moreno J. Flexural ductility of ultra-high-strength concrete members. ACI Structural Journal, 1989, 86, No. 6, 394-400.

9. Sarkar S., Adwan 0. and Munday J. G. L. High strength concrete: an investigation of the flexural behaviour of high strength rc beams. Structural Engineer, 1997, 75, No. 7, 115-121.

10. PARK R. Ductility evaluation from laboratory and analytical testing. Proceedings of the 9th World Conference on Earthquake Engineering, Vol. VIII, Tokyo-Kyoto, 1988, 
11. Working Party of The Concrete Society. Technical Report No.49: Design Guidance for High Strength Concrete. The Concrete Society, Slough, UK, 1998.
12. BRITISH STANDARDS InSTITUTION. Structural Use of Concrete, Code of Practice for Design and Construction. BSI, London, 1997, BS 8110: Part 1.

Please email, fax or post your discussion contributions to the secretary: email: lyn.richards@ice.org.uk; fax: +44 (0)20 7799 1325; or post to Lyn Richards, Journals Department, Institution of Civil Engineers, I-7 Great George Street, London SWIP 3AA. 